COGNITIVE

NEUROSCIENCE

\section{Emergence of reflexivity relation without identity matching-to-sample training in hooded crows (Corvus cornix)}

\author{
Maria Samuleeva ${ }^{1,2}$ and Anna Smirnova ${ }^{1}$ \\ ${ }^{1}$ Faculty of Biology, Lomonosov Moscow State University, Leninskiye Gory, 1-12, \\ Moscow, 119192, Russian Federation \\ ${ }^{2}$ Center for Biopsychological Research, Moscow Institute of Psychoanalysis, \\ Kutuzovskij pr., 34, Moscow, 121170, Russian Federation \\ Address correspondence and requests for materials to Maria Samuleeva, \\ samuleeva@gmail.com
}

\begin{abstract}
The ability to form equivalent relations between sign and referent - symbolization - is one of the important cognitive components of language. Equivalent relations have the properties of symmetry (if $A \rightarrow B$ then $B \rightarrow A)$, reflexivity $(A \rightarrow A$, $B \rightarrow B$ ), and transitivity (if $A \rightarrow B$ and $B \rightarrow C$, then $A \rightarrow C$ ). The current study evaluates whether reflexivity can be spontaneously revealed in hooded crows (Corvus cornix) without training after the formation of the symmetry relation. These birds were previously taught an arbitrary matching-to-sample task with the letters "S" and "V" as samples, and sets of images (same-sized and different-sized figures) as comparisons. Positive results in the transfer tests showed that the crows associated letters with the concepts of sameness/difference. After that, they successfully passed the symmetry test, in which samples and comparisons were switched around. In the present experiment we found out that the crows passed the reflexivity test $(A \rightarrow A, B \rightarrow B)$ without identity training. We hypothesize that if the subject associates the sample not with certain stimuli but rather with concepts, it facilitates the formation of equivalence relations between them.
\end{abstract}

Keywords: equivalence, reflexivity, symmetry, concept formation, identity matching-to-sample, arbitrary matching-to-sample, hooded crows.

\section{Introduction}

In human language, relations between sign and referent are equivalent (Carr and Felce, 2000; Burlak, 2018). By definition (Sidman et al., 1982; Sidman and Tailby, 1982), equivalent relations have the properties of symmetry (if stimulus B is matched to stimulus $A$, then stimulus $A$ is matched to stimulus $B$ ), reflexivity (a stimulus is matched to itself, $A \rightarrow A, B \rightarrow B$ ), and transitivity (if $A$ is matched to $B$ and $B$ is matched to $C$, then $A$ is matched to $C$ ).

Specific mechanisms of the formation of equivalence relations may be isolated and investigated in experiments in animals. Sample-comparison equivalence in non-human subjects has been actively studied for the last 35 years (Sidman et al., 1982; Sidman and Tailby, 1982), yet experimental data on this issue are controversial and the mechanisms for the formation of sign-reference equivalence are not clear enough (Lionello-DeNolf, 2009). The matching-to-sample (MTS) task is often used to investigate the mechanisms of equivalence formation. For example, the subject can be trained to match the comparison stimulus $B$ to the sample $\mathrm{A}(\mathrm{A} \rightarrow \mathrm{B}$, arbitrary matching-to-sample task). Then, after training the test can reveal whether subjects can exhibit untrained relations of symmetry $(B \rightarrow A)$ or reflexivity $(\mathrm{A} \rightarrow \mathrm{A}$ and $\mathrm{B} \rightarrow \mathrm{B})$. The MTS task can also be used to find out if the subject is capable of performing the trained relation with new stimuli. For example, after training an identity MTS task with certain stimuli $(\mathrm{A} \rightarrow \mathrm{A}, \mathrm{B} \rightarrow \mathrm{B})$, the reflex- 
ivity test with new stimuli reveals whether the subject has learned the reflectivity relation (generalized identity MTS rule); or, after training an arbitrary MTS task with certain stimuli $(A \rightarrow B, B \rightarrow A, C \rightarrow D)$, the symmetry test $(D \rightarrow C)$ reveals whether the subject has learned the symmetry relation.

Positive results in these tests are infrequent and usually appear only after the training of another equivalence property. For instance, one of three chimpanzees (Pan troglodytes; Tomonaga, Matsuzawa, Fujita and Yamamoto, 1991) passed the symmetry test $(B \rightarrow A)$ after not only arbitrary MTS $(A \rightarrow B)$, but also identity MTS training (reflexivity training: $A \rightarrow A, B \rightarrow B$ ). The positive result in the symmetry test is probably due to the fact that during identity training, the subject learned that the same stimulus (A1 and A2; B1 and B2) can be used both as sample and as comparison (e.g., Frank and Wasserman, 2005), which demonstrates not only reflectivity relations, but also symmetrical relations $(\mathrm{A} 1 \rightarrow \mathrm{A} 2 ; \mathrm{A} 2 \rightarrow \mathrm{A} 1 ; \mathrm{B} 1 \rightarrow \mathrm{B} 2 ; \mathrm{B} 2 \rightarrow \mathrm{B} 1)$. Positive results of the symmetry test after identity and arbitrary training with the same stimuli were received in one of three capuchin monkeys (Cebus apella; Santos et al, 2003) and both of two pigeons (Columba livia; Frank and Wasserman, 2005). However, the demonstration of one equivalence property does not guarantee another. For example, three language-trained chimpanzees failed the symmetry test $(\mathrm{B} \rightarrow \mathrm{A})$ after identity $(\mathrm{A} \rightarrow \mathrm{A}, \mathrm{B} \rightarrow \mathrm{B})$ and arbitrary training $(A \rightarrow B$; Dugdale and Lowe, 2000).

Long-lasting scrupulous pigeon studies by P.J. Urcuioli and colleagues (e.g., Sweeney and Urcuioli, 2010; Urcuioli, 2011; Urcuioli and Swisher, 2012; Swisher and Urcuioli, 2018) made a substantial contribution to this field of research. Pigeons were trained and tested through the use of the go/no go procedure: sample and comparison are demonstrated one after the other at the same location. According to Urcuioli's (2008) theory, the properties of the matching stimuli include their location and ordinal position within a trial (e.g., the sample stimulus is not just " $\mathrm{A}$ " but "A-on-the-center-key-in-the-firstordinal-position"). The sample and comparison stimuli on the reinforced successive matching baseline trials become members of the same stimulus class. The elements common to more than one class will cause their respective smaller classes to merge into larger ones, and the stimuli become members of an equivalence class. Urcuioli's theory provides the theoretical basis for predicting the emergence of reflexivity, symmetry and transitivity relations in the equivalence class members. Experimental results provide support for Urcuioli's (2008) theory, but not always (e.g., Sweeney and Urcuioli, 2010; Urcuioli and Swisher, 2012). This means that something other than the mechanisms proposed in the theory account for the overall pattern of observed results.

In most of the studies, the training and testing procedures use a limited number of stimuli (e.g., Tomonaga,
Matsuzawa, Fujita and Yamamoto, 1991; Dugdale and Lowe, 2000; Frank and Wasserman, 2005; Swisher and Urcuioli, 2018). As a result, the animal is trained several "if, then" relations: if the sample is A1, then choose B1 as comparison; if the sample is A2, then choose B2 as comparison, and so on. We believe that if the subject associates the samples not with separate comparisons but with concepts, it might facilitate the formation of equivalence relations. Similar ideas are shared by other authors (Medam, Marzouki, Montant and Fagot, 2016): stimulus equivalence and categorization are closely related (e.g., in language, the referent of a word usually corresponds to a category rather than a particular object), and category learning might promote equivalence. In our opinion, this is evidenced by the results of I. M. Pepperberg (2006). A grey parrot (Psittacus erithacus) named Alex was previously trained to vocally produce English quantity labels for sets of up to six items. He was able to perform the task with novel items (Pepperberg and Gordon, 2005), therefore, he matched quantity labels not only to particular sets of items but to concepts of number. After that the parrot spontaneously revealed transitivity: Alex associated Arabic numbers with their relevant physical quantities $(\mathrm{B} \rightarrow \mathrm{C}$ and $\mathrm{C} \rightarrow \mathrm{B})$ after being trained to match vocal quantity labels to the set of items and vice-versa $(\mathrm{A} \rightarrow \mathrm{B} ; \mathrm{B} \rightarrow \mathrm{A})$ and to identify Arabic numerals 1-6 with the same vocal labels and vice-versa $(C \rightarrow A ; A \rightarrow C$; Pepperberg, 2006). We obtained similar results (Smirnova, Lazareva and Zorina, 2002; Smirnova, 2011): crows that previously formed the generalized IMTS rule were able to spontaneously establish a correspondence between Arabic numerals 1-8 and the number of elements in the images $(\mathrm{A} \rightarrow \mathrm{C}$ and $\mathrm{C} \rightarrow \mathrm{A}$ ) by comparing the previously obtained information about the number of mealworms corresponding to the Arabic numeral $(\mathrm{A} \rightarrow \mathrm{B})$ or the number of elements in the images $(C \rightarrow B)$.

In order to test the assumption that if the subject associated the samples with the concepts, it might facilitate the formation of equivalence relations, we taught two groups of hooded crows (Corvus cornix) to match the image of the letter " $\mathrm{S}$ " as a sample to images of same-sized figures as a comparison (circles, squares, or triangles, etc.) and the image of the letter " $V$ " as a sample to images of different-sized figures as a comparisons (Samuleeva and Smirnova, 2019a, b). The process of learning was extremely long. For example, the birds had been taught to match " $S$ " as a sample to an image of same-sized circles as a comparison and " $V$ " as a sample to an image of different-sized circles as a comparison after more than 4000 trials. After being taught the arbitrary MTS tasks with 12 comparisons (six images of identical-sized figures and six images of different-sized figures), two crows reliably transferred discriminative responding to new stimuli from the same categories that were used in training (same-sized or different-sized 
figures) as well as to stimuli from a different category (same-shape or different-shape figures). Positive results in the transfer tests showed that the crows associated letters "S" and "V" with the concepts of sameness/difference. After that, they successfully passed the symmetry test, in which samples and comparisons were switched around (Samuleeva and Smirnova, 2019a, b). With these results, one might argue that samples and comparison become equivalent. Another argument for this would be a positive result of the reflexivity test.

Reflexivity is demonstrated when the subject that has been trained to relate various identical stimuli can do so immediately and accurately when presented completely novel stimuli (identity matching-to-sample; Schusterman and Kastak, 1993) or when the subject performs an identity matching-to-sample task spontaneously, without direct training, after symmetry or transitivity training (Sweeney and Urcuioli, 2010; Swisher and Urcuioli, 2018). However, not everyone agrees that reflexivity is the same as generalized identity (e.g., Saunders and Green, 1992; Swisher and Urcuioli, 2018).

As far as we know, the only data on reflexivity emergence were obtained by Urcuioli and colleagues. Sweeney and Urcuioli (2010), Urcuioli (2011), and Urcuioli and Swisher (2012) reported that most of their pigeons (four of four in Urcuioli, 2011; five of six in the other two studies) demonstrated reflexivity on $A \rightarrow A$ probe-test trials after they were trained on $\mathrm{A} \rightarrow \mathrm{B}, \mathrm{B} \rightarrow \mathrm{A}$, and $\mathrm{B} \rightarrow \mathrm{B}$ identity successive matching. According to the authors, the test results can be explained not only by Urcuioli's (2008) theory of pigeon stimulus-class formation, but also by the generalized identity matching interpretation. We, however, believe that the second explanation is unlikely because it is quite difficult to get pigeons to demonstrate full same/different concept learning (e.g., they needed to be trained 256 unique stimuli combinations; Wright and Katz, 2006). The first demonstration of true reflexivity emergence based solely on arbitrary matching reinforcement contingencies was provided by Swisher and Urcuioli (2018): the pigeons showed evidence for reflexivity after concurrent training on successive $A \rightarrow B$, $\mathrm{B} \rightarrow \mathrm{C}$, and $\mathrm{A} \rightarrow \mathrm{C}$ matching.

Previously, we examined same-different conceptualization by hooded crows (Smirnova, Lazareva and Zorina, 2000; Smirnova, Zorina, Obozova and Wasserman, 2015). After long, repeated training of an identity MTS task with several different kinds of visual stimuli (single stimuli of varying colors or shapes and clusters of stimuli containing varying numbers of items), the crows reliably transferred discriminative responding to new stimuli from the same categories that were used in training (other colors, shapes, and numbers of items), as well as to stimuli from a different category (stimuli varying in size), suggesting that the birds had acquired a general rule based on physical identity. The rule was applicable even to novel two-item sample and comparison stimuli involving only relational sameness (analogical reasoning task; Smirnova, Zorina, Obozova and Wasserman, 2015).

In the current experiments, we seek to find out if the property of reflexivity (matching stimuli to themselves) can emerge without identity matching training in hooded crows that were previously taught an arbitrary MTS task, associated the letters "S" and "V" with the concepts of sameness/difference, and passed the symmetry test successfully.

\section{Method}

The subjects were two hooded crows (Corvus cornix L.) at least two years old. Both birds were delivered to the laboratory after treatment in a veterinary hospital following injury in the wild. As was described in the introduction, the crows (Crow 1, Samuleeva and Smirnova, 2019b; and Crow 2, Samuleeva and Smirnova, 2019a) had been previously taught an arbitrary MTS task, associated the letters " $\mathrm{S}$ " and "V" with the same/different concepts, and then had passed the symmetry test $(\mathrm{B} \rightarrow \mathrm{A})$.

The birds were housed in small groups in the aviary of the Biology Department of Lomonosov Moscow State University, Russia. Throughout the experiment, the birds had free access to water. The tests were carried out in spring 2015 (Crow 1) and spring 2018 (Crow 2).

A wire mesh cage $(70 \times 35 \times 35 \mathrm{~cm})$ and a plastic tray $(20 \times 30 \mathrm{~cm})$ with a handle were used (Fig. 1). Before each trial, the tray was prepared out of sight of the bird. Two cups were placed on the tray. The cards (comparison stimuli) covered the cups. The sample stimulus was placed between the comparison stimuli. All the images on the stimuli were printed on cardboard cards

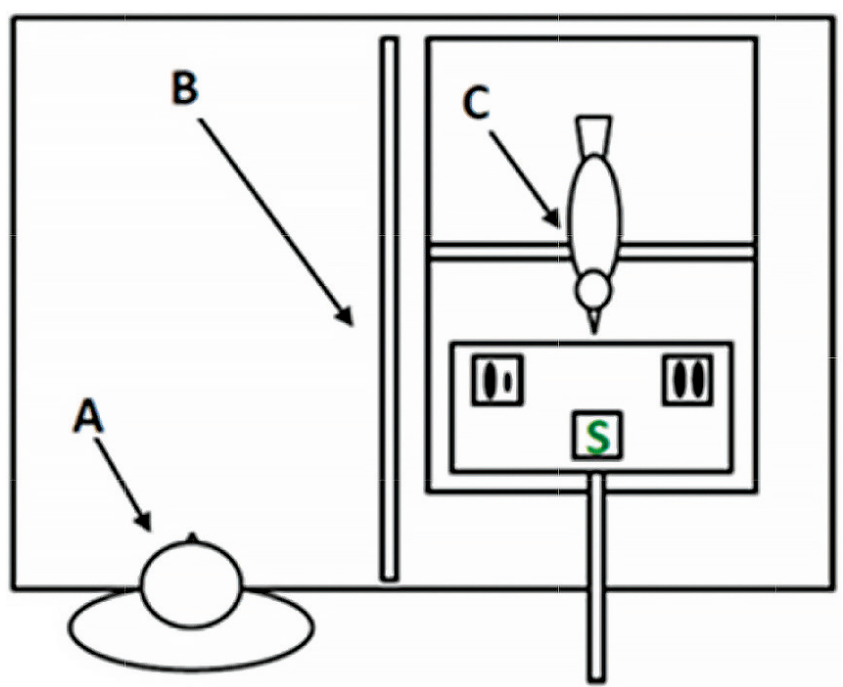

Fig. 1. Experimental design. A - experimenter, B - opaque screen, C - crow. 


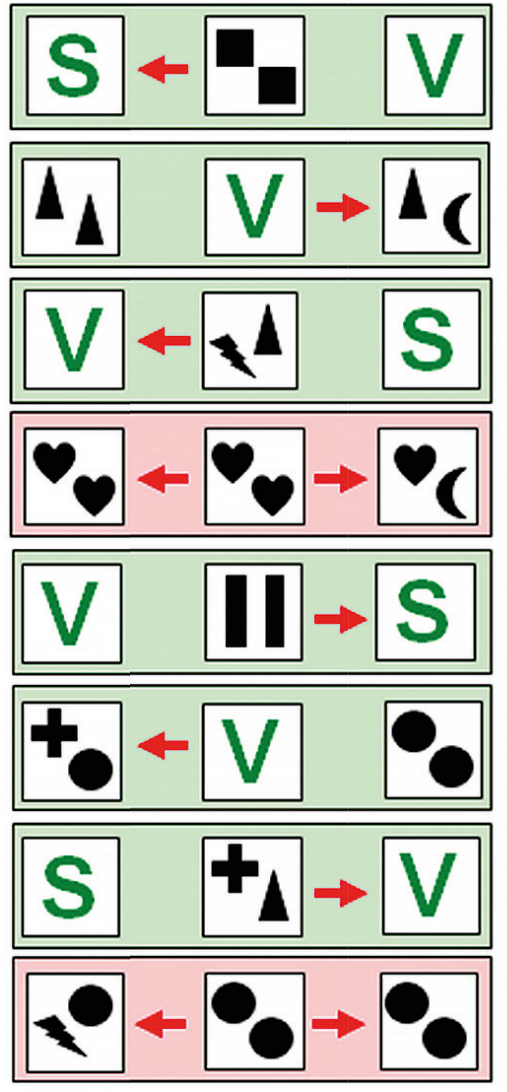

Test 1
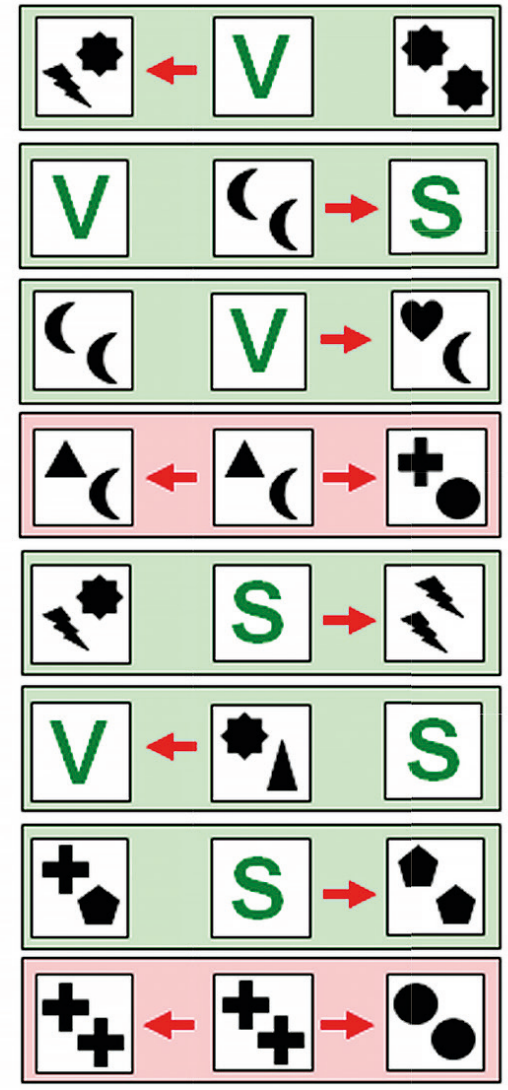

Test 2
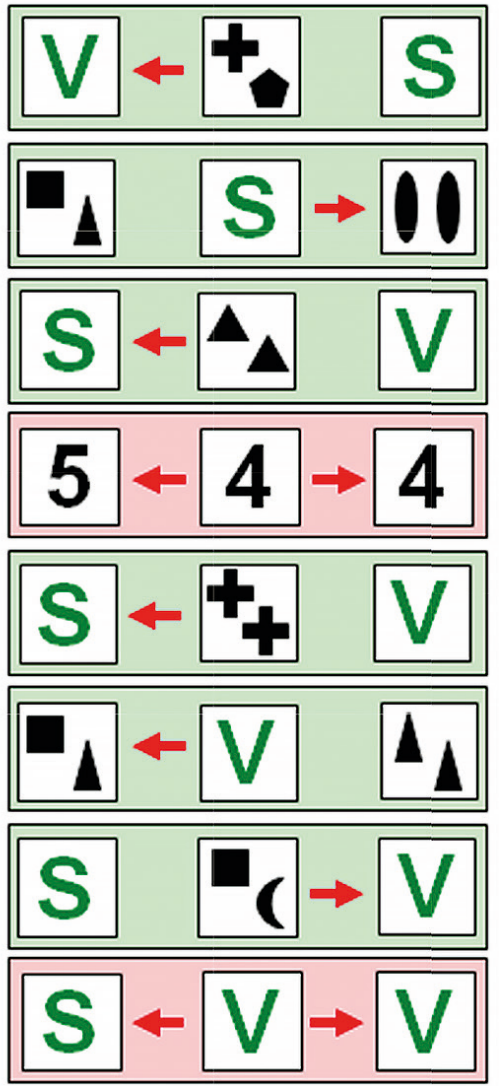

Test 3

Fig. 2. Examples of baseline (green background) and test (pink background) trials in three reflexivity tests. The reinforced stimulus in each trial is indicated by an arrow.

$(7 \times 7 \mathrm{~cm})$. In order to prevent the bird's accidental training during the test, identity test trials were intermixed with arbitrary matching baseline ones: each of the three baseline trials were followed by one test trial (Fig. 2). In baseline trials, one cup contained two mealworms and the other cup was empty (so the crow accesses food only after a correct choice), whereas in testing trials both cups contained mealworms. An opaque plastic screen was placed between the experimenter and the crow: neither the bird nor the experimenter could see one another, precluding a "Clever Hans" effect. The procedure of two-alternative simultaneous MTS is described in more details elsewhere (Smirnova, Lazareva and Zorina, 2000; Smirnova, Zorina, Obozova and Wasserman, 2015).

We conducted three reflexivity tests (Fig. 2). In all baseline trials (arbitrary MTS task) if the sample was the letter "S" or "V", then comparisons were images of sameand different-shape figures; if the sample was an image of figures, then the comparisons were the letters " $\mathrm{S}$ " and "V". The birds had successfully performed arbitrary matching to sample with these stimuli earlier (Samuleeva and Smirnova, 2019a, b). In the test trials, the sample was the same as one of the comparisons (identity MTS task). Each of the 1 st and 2 nd tests contained 24 test and 72 baseline trials. The stimuli in the tests trials were 12 images of same-shape figures and 12 images of different-shape figures. Test stimuli combinations were never repeated within the test (they were presented only once). On the 1st test in each test trial, one comparison was an image of same-shape figures while another comparison was an image of different-shape ones. On the 2nd test in each of the 24 test trials, both comparisons were images of either same-shape or different-shape figures. The 3rd test included 24 test trials in which the stimuli were new images (numerical symbols 1-8; stimuli combinations were never repeated within this part of the test); 24 test trials in which the stimuli were the letters " $\mathrm{S}$ " and "V"; and 144 baseline trials. Test trials with the numerical symbols and with the letters in the test were intermixed. For statistical analysis we used STATISTICA for Windows 7; significance as compared with chance accuracy level (50\%) estimated for binomial distribution; in order to determine the significance of differences between two proportions we used the two-tailed z-test.

This research was conducted in compliance with EU Directive 2010/63/EU. 


\section{Results and discussion}

In Test 1 the percentage of correct choices for Crow 1 was $75 \%(\mathrm{n}=24, \mathrm{p}=0.003)$ on the test trials and $66.7 \%$ $(\mathrm{n}=72, \mathrm{p}=0.001)$ on the baseline trials with insignificant difference between percentages of correct choices in the baseline and the test $(\mathrm{p}=0.447)$. Because of the low level of performance in the baseline trials we conducted an additional arbitrary MTS session with the baseline trials. Performance in this session did not improve in more than 1000 trials, so this bird did not participate in Tests 2 and 3.

In Test 1 the percentage of correct choices for Crow 2 was $79.2 \%(\mathrm{n}=24, \mathrm{p}=0.001)$ on the test trials and $80.6 \%(n=72, p<0.001)$ on the baseline match trials. The difference between the percentages of correct choices in the baseline and the test trials was insignificant $(\mathrm{p}=0.881)$. Crow 2 also succeeded in Tests 2 and 3. The bird revealed performance at above chance level in the 2 nd test with percentage of correct choices as follows: $83.3 \%(n=24, p<0.001)$ in the test trials and $75.0 \%$ $(\mathrm{n}=72, \mathrm{p}<0.001)$ in the baseline trials with insignificant difference between them $(\mathrm{p}=0.401)$.

In the 3 rd test performance in the test trials was $81.3 \%(\mathrm{n}=48, \mathrm{p}<0.001)$. Crow 2 succeeded in both types of test trials: when stimuli were numerical symbols $(87.5 \%, \mathrm{n}=24, \mathrm{p}<0.001)$ and when stimuli were the letters "S" and "V" $(75 \%, \mathrm{n}=24, \mathrm{p}=0.003)$. In the trials with numerical symbols 1-8 the percentage of correct choices was numerically but not reliably $(p=0.267)$ more than in the trials with the letters. This could be due to the increased interest of the bird to the new stimuli (images of numerical symbols 1-8). The percentage of correct choices in 144 baseline trials was $81.9 \%(\mathrm{p}<0.001)$ with no significant difference between the baseline and test trials with numerical symbols $(\mathrm{p}=0.503)$ and letters " $\mathrm{S}$ " and "V" ( $\mathrm{p}=0.424)$.

There were neither numerical $(79.2 \%, 83.3 \%$, $81.3 \%)$ nor reliable differences between the percentages of correct choices in the 1st and the 2nd tests $(\mathrm{p}=0.711)$ and the 1 st and the 3rd tests $(\mathrm{p}=0.441$, $\mathrm{p}=0.418$ ). That is one reason why we argue that positive test results cannot be due to learning during the tests. Another argument that learning was also unlikely is that in the test trials we reinforce both correct and incorrect choices. In addition to this, in all test trials (except ones with the letters " $S$ " and " $V$ " in the 3rd test), the stimuli combinations were never repeated within the test and were presented only once. Furthermore, it was shown that the crows needed thousands of trials to learn the identity MTS task (Smirnova, Lazareva and Zorina, 2000). All of the above supports the point of view that the crows in our current experiment could not learn the identity MTS task through a limited number of unique test trials.
Thus, we found out that the crows can perform the identity matching-to-sample task without explicit training, i.e., they can spontaneously reveal the reflexivity relation. As far as we know, only Swisher and Urcuioli (2018) had demonstrated this emergent relation based only on arbitrary MTS training. Previously we found out that the crows can spontaneously reveal the symmetry relation (Samuleeva and Smirnova, 2019a, b). Taken together the results indicate that relations between samples (letters "S" and "V") and the comparisons (concepts of sameness/difference) are equivalent. These relations became equivalent after the arbitrary MTS training during which the birds associated each sample with a set of stimuli with shared features (Samuleeva and Smirnova, 2019a, b).

During arbitrary MTS training the crows first learned several "if, then" rules: e.g., if the sample is "S", then choose the image of same-sized figures, and if the sample is " $V$ ", then choose the image of different-sized figures. After long arbitrary MTS training with two sets of stimuli with shared features (six images of same figures and six images of different figures), positive results of the transfer tests with new comparisons allow us to argue that the birds have associated the samples (letters " $S$ " and "V") with categorical representations of objects - the concepts of sameness/difference. Thereby the birds had acquired a general matching rule: if the sample is " $S$ ", then choose the image of same figures; if the sample is " $V$ ", then choose the image of different figures. Positive results of the symmetry test (Samuleeva and Smirnova, 2019a, b) and the reflexivity test allow us to argue that the letters " $\mathrm{S}$ " and " $\mathrm{V}$ " and concepts of sameness/difference became equivalent. Therefore, to solve the task, an even more general matching rule has become applicable - choose a comparison equivalent to the sample. Only the formation of such a general matching rule explains why the crow passed reflexivity tests not only with familiar stimuli, but also with new ones - numerical symbols 1-8 (Samuleeva and Smirnova, 2019a).

Our results support the hypothesis that if the subject associated the sample not with certain stimuli but with concepts, then it facilitates the formation of equivalence relations between them.

\section{Conclusion}

We have found evidence for the emergence of reflexivity without identity matching training in hooded crows. Our results may indicate that the acquisition of categorical representations of objects (or concepts) might promote the emergence of equivalence between these categories and the labels to which they are associated, and, consequently, symmetry and reflexivity relations between them.

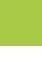




\section{References}

Burlak, S. A. 2018. Origin of the language: facts, studies, hypotheses. Alpina non-fiction, Moscow. (In Russian)

Carr, D. and Felce D. 2000. Application of stimulus equivalence to language intervention for individuals with severe linguistic disabilities. Journal of Intellectual and Developmental Disability 25(3):181-205. https://doi. org/10.1080/13269780050144262

Dugdale, N. and Lowe, C. F. 2000. Testing for symmetry in the conditional discriminations of language-trained chimpanzees. Journal of the Experimental Analysis of Behavior 73(1):5-22. https://doi.org/10.1901/jeab.2000.73-5

Frank, A.J. and Wasserman, E. A. 2005. Associative symmetry in the pigeon after successive matching-to-sample training. Journal of the Experimental Analysis of Behavior 84(2):147-165. https://doi.org/10.1901/jeab.2005.11504

Lionello-DeNolf, K. M. 2009. The search for symmetry: 25 years in review. Learning \& behavior 37(2):188-203. https://doi.org/10.3758/LB. 37.2.188

Medam, T., Marzouki, Y., Montant, M., and Fagot, J. 2016. Categorization does not promote symmetry in Guinea baboons (Papio papio). Animal Cognition 19(5):987-998. https://doi.org/10.1007/s10071-016-1003-4

Pepperberg, I. M. 2006. Ordinality and inferential abilities of a Grey Parrot (Psittacus erithacus). Journal of Comparative Psychology 120:205-216. https://doi.org/10.1037/07357036.120.3.205

Pepperberg, I. M. and Gordon, J. D. 2005. Number comprehension by a grey parrot (Psittacus erithacus), including a zero-like concept. Journal of Comparative Psychology 119(2):197-209. https://doi.org/10.1037/07357036.119.2.197

Samuleeva, M. V. and Smirnova, A. A. 2019a. The study of sigh learning process in hooded crows. Herald of Tver State University 1(53):203-217. (In Russian) https://doi. org/10.26456/vtbio61

Samuleeva, M. V. and Smirnova, A. A. 2019b. Study of symbolization process in hooded crows. Zh Vyssh Nerv Deiat I $P$ Pavlova 69(4):505-513. (In Russian)

Santos, J. R., Barros, R. S., and Galvão, O. Symmetry in Cebus apella. 29th Annual Meeting of the Association for Behavior Analysis. San Francisco. 2003.

Saunders, R. R. and Green, G. 1992. The nonequivalence of behavioral and mathematical equivalence. Journal of the Experimental Analysis of Behavior 57:227-241. https://doi. org/10.1901/jeab.1992.57-227

Schusterman, R. J. and Kastak, D. A. 1993. California sea lion (Zalophus californianus) is capable of forming equivalence relations. The Psychological Record 43(4):823-839. https://doi.org/10.1007/BF03395915
Sidman, M., Rauzin, R., Lazar, R., Cunningham, S., Tailby, W., and Carrigan, P. 1982. A search for symmetry in the conditional discriminations of rhesus monkeys, baboons, and children. Journal of the Experimental Analysis of Behavior 37(1):23-44. https://doi.org/10.1901/jeab.1982.37-23

Sidman, M. and Tailby, W. 1982. Conditional discrimination vs. matching to sample: an expansion of the testing paradigm. Journal of the Experimental Analysis of Behavior 37(1):5-22. https://doi.org/10.1901/jeab.1982.37-5

Smirnova, A. A. 2011. On the capability of birds for symbolization. Biology Bulletin 38(9):878-884. https://doi. org/10.1134/S106235901109007X

Smirnova, A. A., Lazareva, O. F., and Zorina, Z. A. 2000. Use of number by crows: investigation by matching and oddity learning. Journal of the Experimental Analysis of the Behavior 73:163-176. https://doi.org/10.1901/jeab.2000.73-163

Smirnova, A. A., Lazareva, O. F., and Zorina, Z. A. 2002. Prototype symbolization in hooded crows. Zh Vyssh Nerv Deiat I P Pavlova 52(2):241-254. (In Russian)

Smirnova, A., Zorina, Z., Obozova, T., and Wasserman, E. 2015. Crows spontaneously exhibit analogical reasoning. Current Biology 25(2):256-260. https://doi.org/10.1016/j. cub.2014.11.063

Sweeney, M. M. and Urcuioli, P.J. 2010. Reflexivity in pigeons. Journal of the Experimental Analysis of Behavior 94(3):267282. https://doi.org/10.1901/jeab.2010.94-267

Swisher, M. and Urcuioli, P. J. 2018. Reflexivity without identity matching training: A first demonstration. Journal of the Experimental Analysis of Behavior 109(1):125-147. https:// doi.org/10.1002/jeab.302

Tomonaga, M., Matsuzawa, T., Fujita, K., and Yamamoto, J. H. 1991. Emergence of symmetry in a visual conditional discrimination by chimpanzees (Pan troglodytes). Psychological Reports 68(1):51-60. https://doi.org/10.2466/ pr0.1991.68.1.51

Urcuioli, P.J. 2008. Associative symmetry, antisymmetry, and a theory of pigeons'equivalence-class formation. Journal of the Experimental Analysis of Behavior 90(3):257-282. https://doi.org/10.1901/jeab.2008.90-257

Urcuioli, P.J. 2011. Emergent identity matching after successive matching training, I: Reflexivity or generalized identity? Journal of the Experimental Analysis of Behavior 96(3):329-341. https://doi.org/10.1901/jeab.2011.96329

Urcuioli, P. J. and Swisher, M. 2012. Emergent identity matching after successive matching training. II: Reflexivity or transitivity? Journal of the Experimental Analysis of Behavior 97(1):5-27. https://doi.org/10.1901/jeab.2012.97-5

Wright, A. A. and Katz, J. S. 2006. Mechanisms of same/different concept learning in primates and avians. Behavioural Processes 72:234-254. https://doi.org/10.1016/j. beproc.2006.03.009 